\title{
Seismic Performance Assessment of a Moment-Frame Reinforced Concrete Building Typology
}

\author{
Marsed Leti*, (D), Hüseyin Bilgin (D) \\ EPOKA University, Faculty of Architecture and Engineering, Department of Civil Engineering, Tirana, ALBANIA.
}

\section{Keywords}

Nonlinear Analysis; Seismic Performance; Incremental Dynamic Analysis; Pushover Analysis; Zeus-NL; Reinforced Concrete Building;

\begin{abstract}
This study covers the application of Static and Dynamic nonlinear analysis to an old moment-frame reinforced concrete building. The case study selected is a template one designed in 1982 without shear walls and built throughout Albanian region in the communism era using old standards (KTP 2-78). For the capacity calculation, Pushover analysis is performed using an inverse triangular load pattern. The demand calculation is conducted using Incremental Dynamic Analysis (IDA) as a method which provides the response behavior of the structure from the elastic range until collapse. For the dynamic analysis is used a set of 18 earthquakes with no marks of directivity. Limit states are defined for both Pushover and IDA based on the FEMA 356 guidelines. The mathematical model is prepared in the environment of Zeus-NL, a software developed especially for earthquake applications. The parameters defined for the IDA analysis are $5 \%$ damped first mode spectral acceleration $\left(\mathrm{Sa}_{(\mathrm{T} 1,5 \%)}\right)$ for the intensity measure (IM) and maximum global drift ratio $\left(\theta_{\max }\right)$ for the damage measure (DM). In addition, limit states are selected for the pushover curve as Immediate Occupancy (IO), Life Safety (LS) and Collapse Prevention (CP). Similarly, for the IDA curve the limit states are selected as IO, CP and Global Instability (GI) based on FEMA guidelines. Furthermore, IDA curves are summarized into $16 \%, 50 \%$ and $84 \%$ fractiles as suggested in the literature. Additionally, a comparison between Pushover and IDA median (50\% fractile) is shown from the same graph to illustrate the correlations between performance levels. Finally, structural performance is interpreted based on the outcomes.
\end{abstract}

\section{Introduction}

Earthquakes are one of the most damaging hazards that cause yearly excessive loos of life and livelihood. Around 10,000 people die each year, caused by severe ground shaking, while the economic losses are in the billions of dollars effecting the gross national product of the effected states [1]. Earthquake engineering has become a long and challenging way since its initial stage, and still appears to improve quickly as we face consequences of more and more damages. In the last century major earthquakes have occurred in Albania and numerous buildings have suffered different level of damages. Throughout of its history it is observed that many important cities like Shkodra, Durrës, and Vlora have been destroyed due to severe earthquakes. In this paper the seismic performance assessment of a reinforced concrete (RC) template building in Albania is conducted using nonlinear static and dynamic analysis. These template buildings were designed in 1982 and constructed in different cities in our country according to old building code [2, 3]. Furthermore, Albania has been evaluated as a region with relatively high seismic vulnerability [4, 5, 6]. Recently, On November 26, 2019, western part of Albania was hit by a $6.4 \mathrm{Mw}$ earthquake with epicenter in Durrës, causing major loss in human and buildings [7, 8, 9]. From site investigation it has been observed that most common failures were objected to improper reinforcement and poor material quality due to aging (Figure 1) [10].

Therefore, it establishes the need to assess the performance of the existing reinforced structures as early as possible. The structural capacity is estimated using one the conventional methods such as pushover analysis. The performance levels are defined according to the FEMA 356 guidelines. On the other hand, one of the main targets of Performance-Based Earthquake Engineering (PBEE) is to evaluate the seismic response of the structure as accurate as possible [11]. Consequently, Incremental Dynamic Analysis (IDA) is used for the estimation of the building vulnerability due to the earthquake motion under a set of 18 records. The structural model is analyzed in the environments of Zeus-NL, a finite element software established especially for the earthquake engineering applications [12, 13].
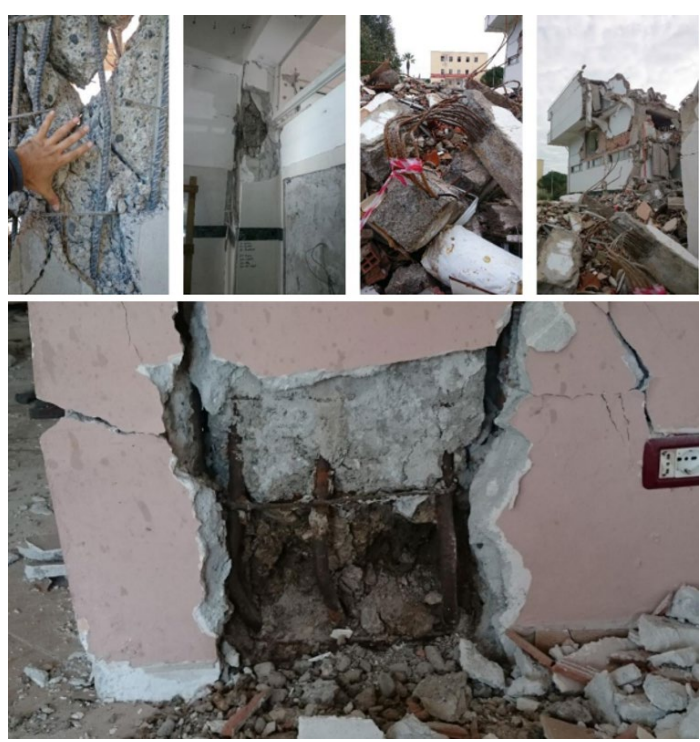

Figure 1: Column failure, corroded rebars, poor concrete quality was observed during the site investigations of the November 26 Earthquake 
Selecting the appropriate ground motion records and an applicable software is crucial while running Incremental Dynamic Analysis. In addition, it requires multiple steps to properly perform the analysis and define the limit states. Initially it is important to prepare a suitable building model in a software which is capable of running IDA. In this study, Zeus-NL package is used to conduct the analysis [13]. Moreover, it must be selected a set of more than ten ground motion records for the dynamic analysis. Then, it is crucial to choose an incrementing method which is compatible with selected software until non-convergence is encountered (e.g, hunt and fill or stepping method). Depending in the software facilities, this step can reduce time and increase the efficiency of the results. Furthermore, it should be defined a suitable intensity measure (IM e.g, 5\% damped first mode spectral acceleration, Sa(11,5\%) for the ground motion and a damage measure (DM e.g, maximum global drift ratio, $\theta_{\max }$ ) [11, 14]. In addition, the IDA curves have to be generated by interpolation for each of the ground motion records after intensity measure and damage measure results are ready. Limit states must be defined according to the respective guidelines and then summarize IDA curves into 16\%, 50\% and $84 \%$ fractiles. Moreover, the interpretation of the seismic structural performance should be done by using the generated information. Additionally, it is provided a methodology on the application of Pushover and Incremental Dynamic Analysis as well as interpretation of the results for this old building template.

\section{Description of the case study building}

First reinforced concrete buildings in Albania started to be constructed after 1990 with the update of the building standards in that time KTP 2-78 [2]. Initially they were designed as template buildings to be constructed in different cities throughout our country. Each of these building templates are considered as the oldest reinforced concrete constructions and their performance evaluation has an urgent need. For the scope of this paper, among various RC templates, "Building Type 82/1" has been selected as a representative of old reinforced concrete buildings in Albania constructed in the communism era. It is designed as residential building in 1982 and is still in use nowadays. The building is $17.3 \mathrm{~m}$ long and $10.0 \mathrm{~m}$ wide. It has 6 bays in its longitudinal direction and 3 frames in the transverse direction (Figure 2).
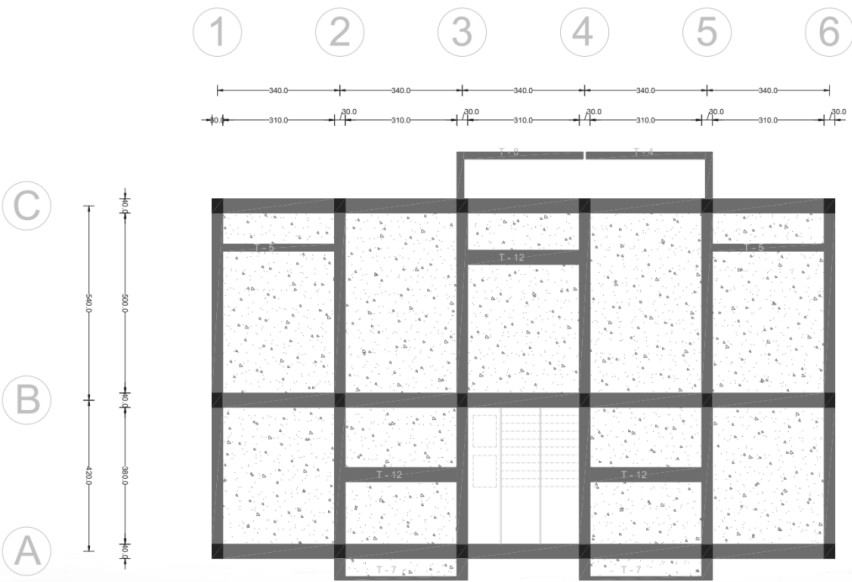

Figure 2: The plan of the case building

In plan, the building is symmetrical in both directions. The structural system is reinforced concrete moment resisting frames without shear walls in any of its directions.

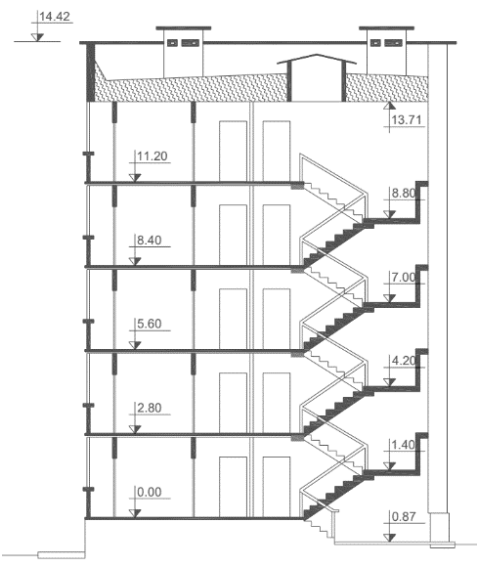

Figure 3: Elevation view of the case building

The building is composed of 5 stories, with a maximum height of $14.42 \mathrm{~m}$. First four stories are $2.8 \mathrm{~m}$ in height and the upper one $3.22 \mathrm{~m}$ as shown in Figure 3. While considering the structural configuration, all elements cast with reinforced concrete. There are 21 columns of $400 * 300 \mathrm{~mm}$ supporting $300 * 200 \mathrm{~mm}$ and $400 * 200 \mathrm{~mm}$ beams.

\subsection{Material characteristics}

The building taken in this paper is located in the city of Durrës and has the same typology, as type $82 / 2$ but bult in different times. The structural design of the building Type $82 / 2$, available by the Central Technical Archive of Construction in Tirana (Figure 4), has been drafted by the Research and Design Institute No. 1 Tirana (ISP). Referring to this project, this typology is conceived as a structure with prefabricated RC frames. This building is designed for areas with a seismic intensity IX (according to the local design notes).

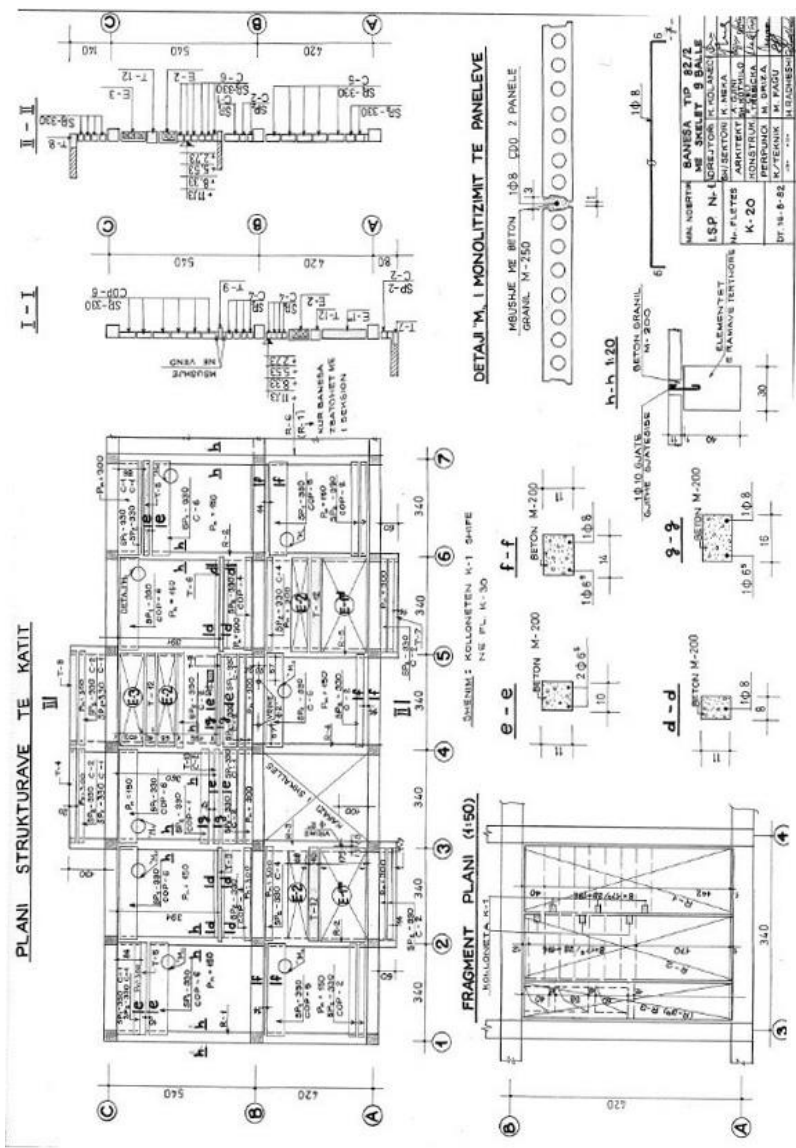

Figure 4: Building details from the original blueprints 
The concrete class has decreased, leading to increased amount of reinforcement of the columns. The studied buildings were constructed as 5- and 6- floors with monolithic RC frame. The structure has no irregularity in plan and in height. The foundations of the building were constructed with two-stepped footing, with different dimensions. Perimetral footings are linked to the head with prefabricated foundation beams, with dimensions $30 \times 40 \mathrm{~cm}$. The transverse reinforcement is designed as $\phi 6$, placed every $100 \mathrm{~mm}$ in critical zone and $200 \mathrm{~mm}$ in the mid-high of columns. Based on the blueprints, the slabs are of prefabricated panels, with holes, $h=110$ $\mathrm{mm}$. Referring to the technical notes in the structural design of this typology, the concrete class is M-200 (C16/20), while reinforcing stee is C-3. Below are given the characteristics of these materials. Detailed specifications on the reinforcement steel and concrete are provided in Table 1 and Table 2 respectively.

Table 1: Properties of Steel Ç-3

\begin{tabular}{ll} 
Characteristics of Reinforcing steel & Ç-3 \\
\hline Characteristic yield strength & $\mathrm{f}_{\mathrm{yk}}=250 \mathrm{MPa}$ \\
Characteristic tensile strength & $\mathrm{f}_{\mathrm{ck}}=250 \mathrm{MPa}$ \\
Modulus of Elasticity & $\mathrm{E}_{\mathrm{s}}=210 \mathrm{GPa}$ \\
Partial factor & $\mathrm{Vs}_{\mathrm{s}}=1.15$ \\
Design yield strength & $\mathrm{f}_{\mathrm{yd}}=215 \mathrm{MPa}$ \\
Design yield for shear & $\mathrm{f}_{\mathrm{ywd}}=180 \mathrm{MPa}$
\end{tabular}

Table 2: Properties of Concrete C16/20

\begin{tabular}{ll}
\hline Characteristics of Concrete & C16/20 \\
\hline $\begin{array}{l}\text { Characteristic compressive cylinder } \\
\text { strength }\end{array}$ & $\mathrm{f}_{\mathrm{ck}}=20 \mathrm{MPa}$ \\
$\begin{array}{l}\text { Characteristic cubic strength } \\
\begin{array}{l}\text { Mean value of concrete cylinder } \\
\text { compressive strength (28 days) }\end{array}\end{array}$ & $\mathrm{f}_{\mathrm{cm}}=16 \mathrm{MPa}\left(\mathrm{f}_{\mathrm{c}, \mathrm{cube}}\right)$ \\
$\begin{array}{l}\text { Mean value of axial tensile strength of } \\
\text { concrete }\end{array}$ & $\mathrm{f}_{\mathrm{ctm}}=2.2 \mathrm{MPa}$ \\
$\begin{array}{l}\text { Characteristic axial tensile strength of } \\
\text { concrete }\end{array}$ & $\mathrm{f}_{\mathrm{ctk}}(5 \%)=1.5 \mathrm{MPa}$ \\
$\begin{array}{l}\text { Characteristic axial tensile strength of } \\
\text { concrete }\end{array}$ & $\mathrm{f}_{\mathrm{ctk}}(95 \%)=2.9 \mathrm{MPa}$ \\
$\begin{array}{l}\text { Secant modulus of elasticity of } \\
\text { concrete }\end{array}$ & $\mathrm{E}_{\mathrm{cm}}=30 \mathrm{GPa}$ \\
$\begin{array}{l}\text { Design value of modulus of elasticity } \\
\text { of concrete }\end{array}$ & $\mathrm{E}_{\mathrm{cd}}=25 \mathrm{GPa}$ \\
$\begin{array}{l}\text { Partial factor for concrete } \\
\begin{array}{l}\text { Design value of concrete compressive } \\
\text { strength }\end{array}\end{array}$ & $\mathrm{f}_{\mathrm{cd}}=\alpha \star \mathrm{f}_{\mathrm{ck}} / \mathrm{Yc}=11.3 \mathrm{MPa}$ \\
\begin{tabular}{l} 
Poisson's ratio \\
\hline
\end{tabular} & $\mathrm{V}=0.20$ \\
\hline
\end{tabular}

For a reliable structural assessment, the proprieties of materials noted in the design papers are considered. From the site inspections, it was found that in one of the buildings, $1^{\text {st }}$ floor collapsed as shown in Figure 5 .

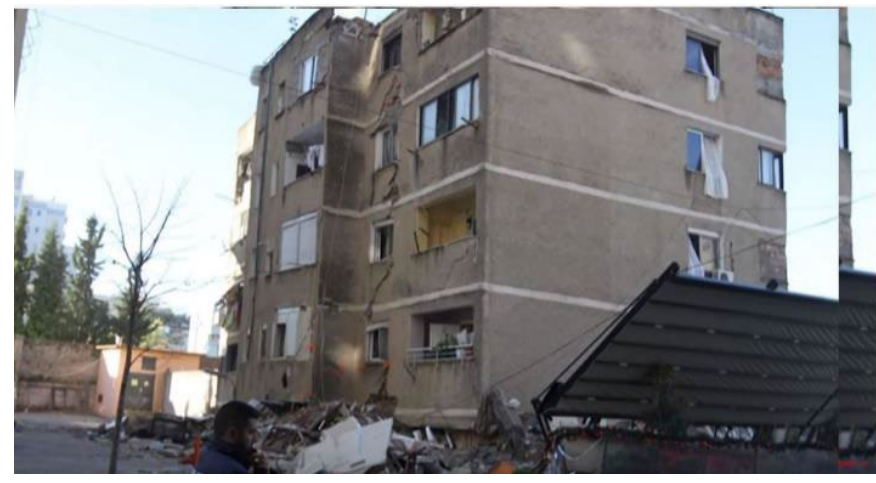

Figure 5: First story collapse of the building template considered in this study
The concrete of the columns on the ground floor was spalled even with the lightest touch due to the use of sea sand and gravel with large fractions (Figure 6). This phenomenon has also been influenced by the use of smooth rebar, which reduces the adhesion to concrete.

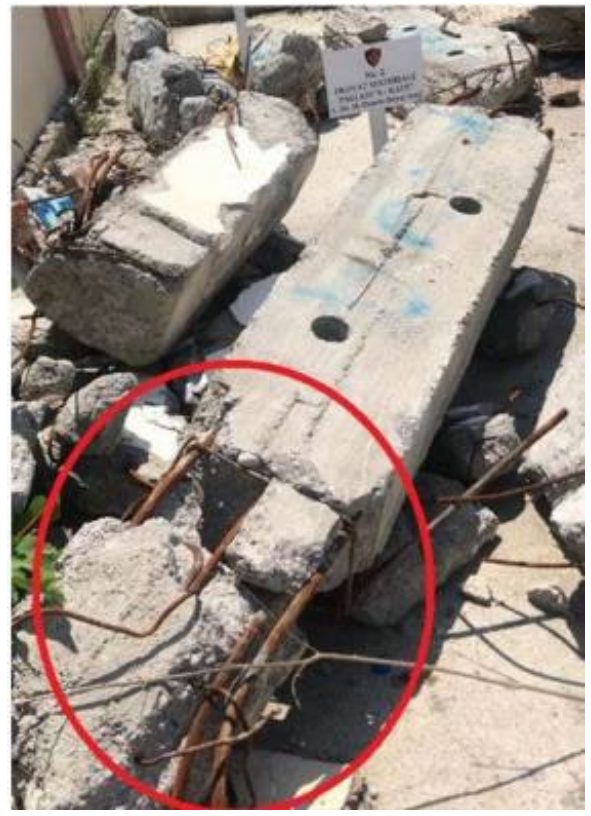

Figure 6: Smooth rebars of columns reinforcement

For the determination of the concrete and steel properties, concrete and steel samples were taken, and laboratory tests were performed. From the tests performed in the building type $82 / 2$, it results that the compressive strength of concrete samples is less than $50 \%$ of design requirements, as shown in Table 3 .

Table 3: Concrete test results

\begin{tabular}{lcc}
\hline Sample (No.) & K1 & K2 \\
\hline Sample height (H) & 77.0 & 77.5 \\
Sample diameter (D) & 75.0 & 75.0 \\
H/D ratio & 1.03 & 1.03 \\
Weight (g) & 778 & 797 \\
Density (g/cm $\left.{ }^{3}\right)$ & 2.287 & 2.328 \\
Load (kN) & 27.9 & 35.6 \\
Compression Strength (MPa) & 6.32 & 8.06 \\
cubic & & \\
\hline
\end{tabular}

Whereas, the steel properties, from the laboratory tests, turn out to be acceptable according to the design definition and the technical conditions (Table 4).

Table 4: Steel tests results

\begin{tabular}{|c|c|c|c|}
\hline Sample (No.) & 1 & 2 & 3 \\
\hline Nominal Diameter (mm) & 14 & 16 & 22 \\
\hline Measured Diameter (mm) & 14.96 & 15.87 & 21.91 \\
\hline Linear weight $(\mathrm{kg} / \mathrm{m})$ & 1.377 & 1552 & 2.958 \\
\hline Cross-sectional area $\left(\mathrm{mm}^{2}\right)$ & 175.4 & 197.66 & 376.75 \\
\hline Tensile strength $\left(\mathrm{N} / \mathrm{mm}^{2}\right) \sigma_{y}$ & 267.6 & 269.4 & 331.8 \\
\hline Ultimate strength $\left(\mathrm{N} / \mathrm{mm}^{2}\right){ }$ u & 402.1 & 400.2 & 469.4 \\
\hline$\sigma_{u} / \sigma_{y}$ Ratio & 1.502 & 1.486 & 1.415 \\
\hline Relative Deformation (\%) & 32.14 & 35.00 & 30.00 \\
\hline
\end{tabular}

\section{Mathematical model}

The analyses performed in this study are conducted using Zeus-NL, a computer program capable of performing static and dynamic analysis [12]. Zeus-NL has been selected as a powerful software which is 
capable of running Incremental Dynamic Analysis. The structural elements of the selected building are modelled using a cubic elastoplastic type 3D element. The bilinear elasto-plastic material model with kinematic strain hardening (stl1) was used for the steel reinforcement. On the other hand, for the concrete it is used uniaxial constant confinement material model (conc2) as given by default in the Zeus-NL package [13]. As shown in the Figure 7, Zeus-NL uses a fiber approach for the nonlinear analyses of the reinforced concrete structures. This is done to monitor the cross-section into different fibers such as unconfined concrete cover, confined concrete fibers and also a separate fiber for the reinforcement. Zeus-NL software has been used effectively by other researchers to investigate the seismic vulnerability of reinforced concrete structures $[15,16,17]$.
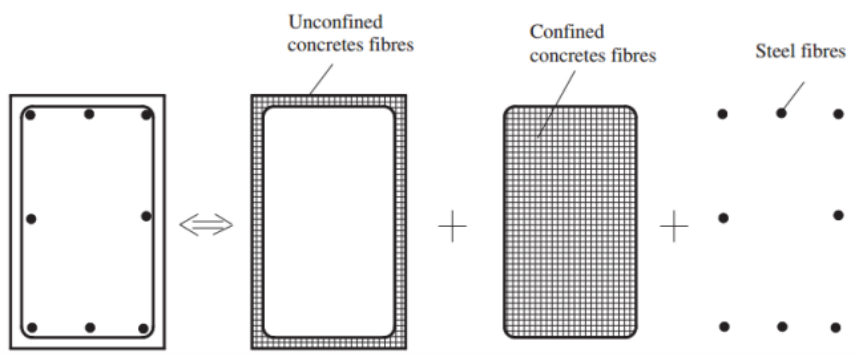

Figure 7: Decomposition of a RC rectangular section into several fibers

The modelling stage in Zeus-NL requires a special attention and could be challenging in complex structures due to its limitations in the user interface. Therefore, to reach the aim of this study we have chosen to model the middle frames of the building, representative of $\mathrm{x}$ and $\mathrm{y}$ directions as shown in Figure 8.
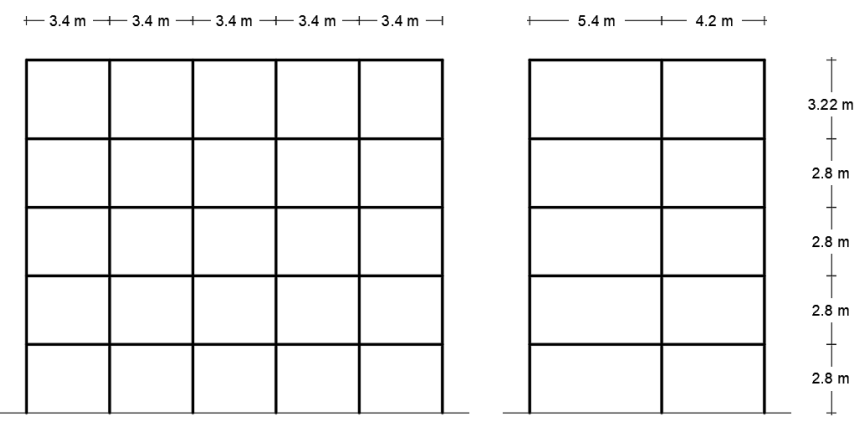

Figure 8: Structural model used in ZeusNL.

$(X$-direction left and $Y$-direction right)

The concrete class given in the blueprint belongs to class $\mathrm{C} 16 / 20$. However, the current condition of these structures indicated a very weak strength of the concrete [18]. Hence, due to aging of these structures we chose to use $\mathrm{C} 16$, as the original material property given in the project details, and $\mathrm{C} 10$ which represent better the actual concrete condition of these template buildings. Consequently, in total there are 4 models which will be analyzed using Pushover and Incremental Dynamic Analysis.

\section{Ground motion records}

IDA procedure requires a set of ground motion records. In literature and by different researchers it is proposed to use ten to twenty earthquakes for midrise buildings to get sufficient results while targeting the estimation of the seismic demand in Incremental Dynamic Analysis [19]. For the scope of this study, it is selected a set of 18 ground motions from a range of 6.5 - 7.1 magnitude as shown in Table 5. To represent a real earthquake scenario the suite of records is selected with no signs of directivity. Two trustful sources are used to collect the data for the Ground motion records: the Pacific Earthquake Engineering Research Centre (PEER) [20] and the U.S Geological Survey (USGS) [21]. Once the template building model is prepared and ground motion records are selected, then nonlinear dynamic analysis can be conducted.

Table 5: The suite of eighteen ground motion records used for this study.

\begin{tabular}{ccccccccc}
\hline No & Event & Year & Station & $\emptyset^{\circ}$ & Soil & M & R/km & PGA/g \\
\hline 1 & Corinth & 1981 & Greece, Corinth & 0 & C & 6.6 & 19.9 & 0.264 \\
2 & Kocaeli & 1999 & Turkey, Duzce & 180 & C & 7.1 & 1.6 & 0.427 \\
3 & Erzincan & 1992 & Turkey, Erzincan & 90 & C & 6.7 & 8.9 & 0.488 \\
4 & Friuli & 1976 & Italy, Tolmezo & 270 & B & 6.5 & 20.2 & 0.345 \\
5 & Imperial Valley & 1979 & Chihuahua & 282 & C,D & 6.5 & 28.7 & 0.254 \\
6 & Imperial Valley & 1979 & Plaster City & 45 & C,D & 6.5 & 31.7 & 0.042 \\
7 & Imperial Valley & 1979 & Westmoreland Fire Station & 90 & C,D & 6.5 & 15.1 & 0.074 \\
8 & Loma Prieta & 1989 & Agnews State Hospital & 90 & C,D & 6.9 & 28.2 & 0.159 \\
9 & Loma Prieta & 1989 & Coyote Lake Dam Downstr. & 285 & B,D & 6.9 & 22.3 & 0.179 \\
10 & Loma Prieta & 1989 & Hollister South \& Pine & 0 & D & 6.9 & 28.8 & 0.371 \\
11 & Loma Prieta & 1989 & Sunnyvale Colton Ave & 270 & C,D & 6.9 & 28.8 & 0.207 \\
12 & Loma Prieta & 1989 & WAHO & 0 & D & 6.9 & 16.9 & 0.370 \\
13 & Loma Prieta & 1989 & WAHO & 90 & D & 6.9 & 16.9 & 0.638 \\
14 & Northridge & 1994 & LA, Hollywood Storage FF & 360 & C,D & 6.7 & 25.5 & 0.358 \\
15 & San Fernando & 1971 & LA, Hollywood Stor. Lot & 90 & C,D & 6.6 & 21.2 & 0.210 \\
16 & San Fernando & 1971 & LA, Hollywood Stor. Lot & 180 & C,D & 6.6 & 21.2 & 0.174 \\
17 & Spitak & 1988 & Armenia, Gukasian & 90 & C & 6.8 & 36.1 & 0.207 \\
18 & Superst. Hill & 1987 & Wildlife Liq. Array & 360 & C,D & 6.7 & 24.4 & 0.200 \\
\hline
\end{tabular}

\section{Structural analysis}

In order to assess the capacity of the selected case study building, several non-linear analyses are performed. Nonlinear Static Analysis also called as Static Pushover Analysis (SPO), was performed to obtain the capacity curve of the structure modelled with concrete C16 and C10. In addition, a recent method introduced in academia known as Incremental Dynamic Analysis (IDA) is conducted using a set of 18 ground motion records. Moreover, a methodology will be presented for the structural analysis considered in this study.

\subsection{Pushover Analysis and performance criteria}

The Pushover analysis is performed in Zeus-NL software using the middle frames for longitudinal and transverse directions. The material properties for the structural elements belong to the uncracked ones as the program updates the section properties under different loading conditions. The pushover curves were developed under the inverted triangular load pattern applied laterally. Furthermore, pushover graphs are plotted from the results obtained from analysis results. The horizontal axis is defined as the displacement of the roof story divided by the building height. On the other hand, the vertical axis represents the base shear normalized by the total weight of the building. Among different procedures to determine the seismic performance levels of structures for the nonlinear static analysis, FEMA 356 guidelines was selected [22, 23, $24,25]$. It provides analytical techniques and principles for the performance-based evaluation of current existing buildings. Performance levels, also called as limit states, are stages in the pushover curve used to indicate the damage intensity while performing the analysis. Based on the FEMA 356 guidelines, Immediate Occupancy (IO), Life Safe (LS) and Collapse Prevention (CP) limit states were selected for the performance assessment (Figure 9). In the IO stage, building is allowed to have light damages. The LS limit stage predicts that building may undergo remarkable damages, however it ensures the structure from collapse. 


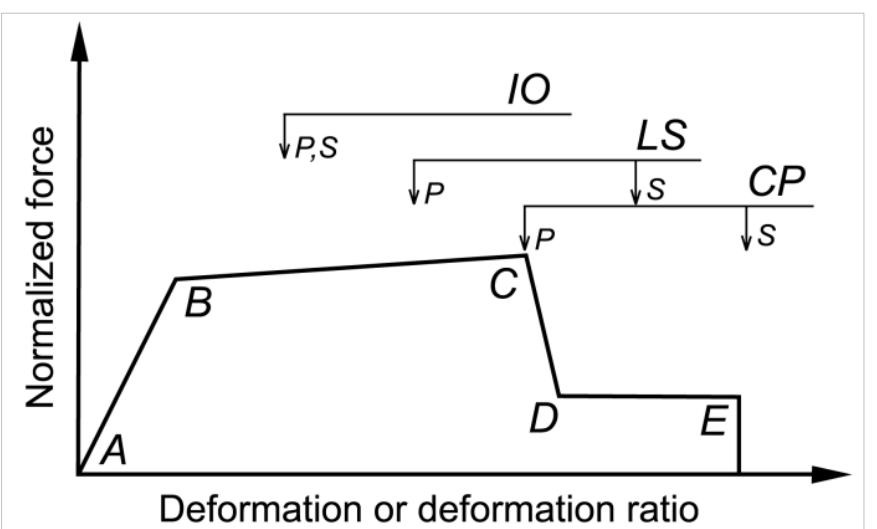

Figure 9: Force-Deformation relationships for concrete elements (FEMA 356)

On the other hand, $\mathrm{CP}$ performance level anticipate the building to remain standing but in the verge of collapsing. For buildings designed properly for seismic loadings and with sufficient member detailing defined as special moment frames (SMF), the suggested values for the global drift ratio are $1 \%$ for the immediate occupancy performance level, $2 \%$ for the life safety and $4 \%$ for the collapse prevention performance level. However, the case building used in this study belongs to the intermediate moment frames (IMF) category. For IMF it has been proposed that global drift ratio limits should be reduced to $0.5 \%$ for the IO performance level, $1 \%$ for the LS and $2 \%$ for the CP performance level [26].

\subsection{Performing Incremental Dynamic Analysis}

Incremental Dynamic Analysis (IDA) [11], also known as Dynamic Pushover Analysis (DPO) [27], was initially proposed in 1977 by Bertero and adopted by the Federal Emergency Management Agency [22]. In addition, the first computer program to implement this analysis was introduced by researchers Vamvatsikos and Cornell [28]. The target of IDA is to monitor the structural performance by continuously increasing the intensity measure of the ground motion records. In other words, it can be defined as a method which replicates time history analysis for each of the records selected. In this way, it forces the structure from the elastic region, to yielding and finally total collapse. One of the most advanced algorithms to predict minimum steps required per record is presented by Vamvatsikos and Cornell as the hunt and fill algorithm [29].

Table 6: IM and DM values from C16-building in $\mathrm{x}$-direction for record No.9

\begin{tabular}{lll}
\hline No. & $\mathrm{Sa}_{(\mathrm{T} 1,5 \%)}$ & $\theta_{\max }$ \\
\hline 1 & 0.001 & 0.036 \\
2 & 0.002 & 0.072 \\
3 & 0.003 & 0.107 \\
4 & 0.003 & 0.143 \\
5 & 0.004 & 0.179 \\
6 & 0.005 & 0.215 \\
7 & 0.007 & 0.251 \\
8 & 0.008 & 0.286 \\
9 & 0.008 & 0.322 \\
10 & 0.009 & 0.358 \\
11 & 0.011 & 0.394 \\
12 & 0.013 & 0.430 \\
13 & 0.014 & 0.465 \\
14 & 0.017 & 0.501 \\
15 & 0.020 & 0.537 \\
16 & 0.023 & 0.573 \\
17 & 0.026 & 0.609 \\
18 & 0.029 & 0.644 \\
19 & 0.033 & 0.680 \\
20 & 0.047 & 0.716 \\
21 & 0.200 & $+\infty$ \\
\hline
\end{tabular}

This algorithm ensures to select the minimum number of runs by appropriately scaling the record. However, in this study it is selected stepping method employed in Zeus-NL software due to its simplicity to understand and implement [30]. Unlike the hunt and fill algorithm which predicts the upcoming intensity step increment, the steeping methods increases constantly until the nonconvergence occurs. In this case it is needed to specify the starting IM, maximum number of dynamic analysis and the preferable IM-step. The IDA calculation parameters involve the scale factor, intensity measure of the earthquake and the damage measure of structural response. The earthquake intensity measure is selected as $5 \%$ damped of first mode spectral acceleration $\mathrm{Sa}_{(\mathrm{T} 1,5 \%)(\mathrm{g})}$ and for the damage measure is considered the maximum global drift ratio $\theta_{\max }(\%)$ as proposed by previous studies [29]. In Table 6, there are shown all steps needed for the analysis together with the structural drift values. The last step ends in the global instability and is denoted by infinite sign. Global instability happens when any small increase in the IM produces huge DM values, essentially ending of the IDA. In total, 21 runs were needed for record \#9 Loma Prieta Coyote Lake Dam Downstream.

\subsection{Interpolation IDA Curves}

As soon as all analysis are ready, IDA curves can be generated. The proper selection of the intensity measure plays an important role in the evaluation of the building performance and interpretation of IDA outcomes [31]. For this study, it is selected 5\% damped of first mode spectral acceleration $\mathrm{Sa}_{(\mathrm{T} 1,5 \%)}$ as intensity measure parameter since the set of ground motions have no signs of directivity and building is a midrise one. On the other hand, we are interested to monitor the rooftop displacement of the building, hence the global drift ratio $\theta_{\max }$ is chosen as damage measure parameter. Once the IM and DM values are gathered from the analysis, then a procedure is determined to interpolate the results for the IDA curves. The interpolation of the results to generate the IDA curves without needing to conduct massive analysis, is done using super spline function and prepared as an algorithm in python programing language. In Figure 10, it is presented the IDA curve which is generated after the interpolation. The dots represent each scale factor of the incremented dynamic analysis plotted in terms of IM and DM selected parameters and the line shows the interpolation from the data collected. Initially it is observed the linear region of the IDA curve which is followed by the first damages occurring. The curve start softening at about $0.48 \mathrm{~g}$ and then reaching the "flatline" after intensity measure of $0.72 \mathrm{~g}$, indicating the global instability where the structure will response with infinite $\theta_{\max }$.

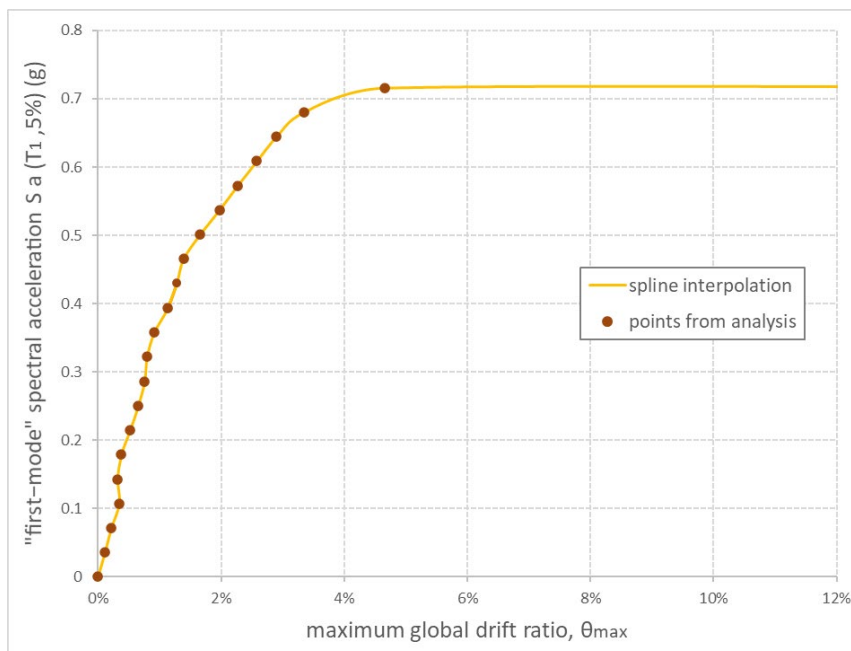

Figure 10. The interpolation of dynamic analyses points for record No.9.

\subsection{IDA Limit States and Fractiles}

Performance-Based Earthquake Engineering requires to define the limit states on the IDA curve to perform the estimation of the building performance [32]. To achieve this target, there are selected three limit states: Immediate Occupancy (IO), Collapse Prevention (CP) which are 
both defined in FEMA guidelines [22] and the Global Instability (GI) as have been previously suggested [11]. Following these guidelines, the immediate occupancy limit state is set to occur at $1 \%$ or 0.01 of the global drift ratio. Moreover, collapse prevention point will be located on the IDA curve when it reaches to $20 \%$ of the elastic slope or when DM goes to $10 \%$. The one occurring first in terms of intensity measure will be selected as $\mathrm{CP}$ point. With great significance here is to properly locate the $\mathrm{CP}$ point when the curve starts softening, still without exceeding $10 \%$ of the DM parameter, so the structural model can be trusted. In some cases, it happens that IDA curve softens and hardens more than one time showing multiple $\mathrm{CP}$ points. According to previous studies, the latest $\mathrm{CP}$ point should be accepted before reaching the $10 \%$ of DM value $[29,30]$. As a final point, global instability occurs when the flatline is reached. This corresponds to huge values of DM, theoretically infinite, caused by any small increase of the IM values. Figure 12 demonstrates the IDA curve and limit states for the first record in X-direction of the C16 Building. The limit states for each record and building are calculated using an algorithm written especially for this purpose in python version 3.7 [33]. Because we set the IM to save approximately 5 to max 20 runs per IDA curve until it reaches the global instability, the results may be not enough to specify each of the limit states in the curve. We could also increase the number of runs, but this would increase tremendously the time to conduct the analysis. Hence, we must use an interpolation method to get the spline curve from the data obtained. For this purpose, we have used "B-spline" interpolation method in python programming language [34] as shown in the example below (Figure 11).

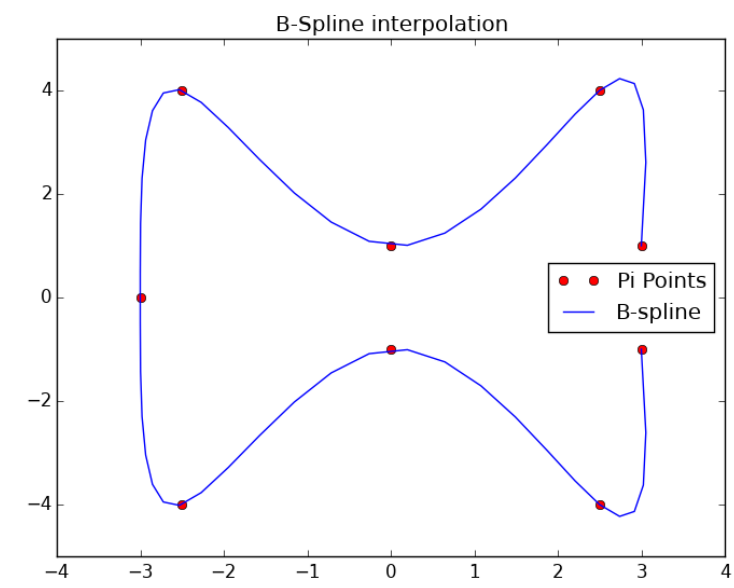

Figure 11: An example of the interpolation using B-spline function in Python programming language

Using just a few points from the analysis, it can predict the whole IDA curve by generating thousands of other coordinate points. By this huge amount of data, we can easily approach to the results of the limit states defined before. In this way, the algorithm not only automates every step but also increases the accuracy of the results and accelerates the process multiple times. Table 7 demonstrates the results generated by the algorithm for each of the limit states in terms of IM and DM parameters.

Table 7. Limit States generated for record No.9

\begin{tabular}{ccccccc}
\multicolumn{3}{c}{$\mathrm{Sa}(\mathrm{T} 1,5 \%)$} & & \multicolumn{3}{c}{$\theta \max$} \\
\cline { 1 - 3 } \cline { 5 - 7 } IO & $\mathrm{CP}$ & $\mathrm{GI}$ & & $\mathrm{IO}$ & $\mathrm{CP}$ & $\mathrm{GI}$ \\
\hline $0.37 \mathrm{~g}$ & $0.67 \mathrm{~g}$ & $0.72 \mathrm{~g}$ & & $1 \%$ & $3.17 \%$ & $+\infty$
\end{tabular}

As demonstrated in Figure 12, with "+" sign it is shown the IO limit state, with "red dot" the collapse prevention and finally with horizontal line, the global instability or structural collapse.



Figure 12. Defining IO and CP limit states in IDA curve for record No.9

Furthermore, summarizing IDA curves into different percentiles will provide large amount of data for the structural response behavior under the suite of ground motions selected. Therefore, it is calculated the $16 \%, 50 \%$ and $84 \%$ percentile values using one of the methods proposed in previous studies [30]. In addition, fractile values of IM and DM are interpolated to generate finally the IDA fractile curves from all earthquakes records we have selected for this case study.

Using the fractiles in a proper way, provides sufficient information in terms of demand calculation. As shown in Figure 13, when $\mathrm{Sa}(\mathrm{T} 1,5 \%)=0.2 \mathrm{~g}, 16 \%$ of the records produce $\theta_{\max }=0.5 \%, 50 \%$ of records produce $\theta_{\max }<0.7 \%$ and $84 \%$ of the records produce $\theta_{\max }<1.1 \%$. Alternatively, the fractiles can be used in the inverse way to get more practical information. Therefore, in order to get demand $\theta_{\max }=3.0 \%$, $16 \%$ of the records have to be scaled to $\mathrm{Sa}(\mathrm{T} 1,5 \%) \geq 0.96 \mathrm{~g}, 50 \%$ of records to $\mathrm{Sa}(\mathrm{T} 1,5 \%) \geq 0.54 \mathrm{~g}$ and $84 \%$ of the records should be scaled to $\mathrm{Sa}(\mathrm{T} 1,5 \%) \geq 0.40 \mathrm{~g}$.

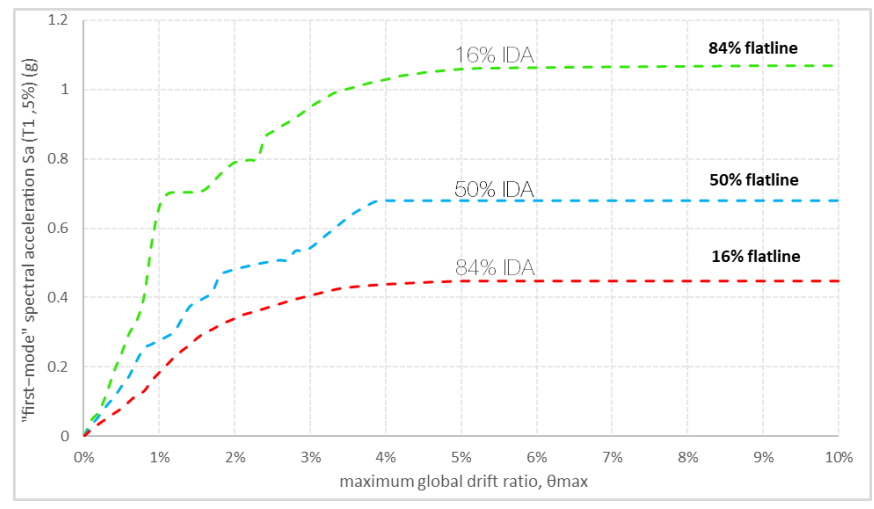

Figure $13.16 \%, 50 \%$ and $84 \%$ IDA fractiles

\section{Results}

\subsection{Pushover results}

Pushover data is obtained from the nonlinear static analysis using an inverse triangular load pattern applied laterally to the frame models in $\mathrm{x}$ and $\mathrm{y}$ direction. Moreover, the limit states are plotted in the same graph with the capacity curves. The models defined with concrete C16 obviously show higher strength capacity for both $\mathrm{x}$ and $\mathrm{y}$ directions as shown in Figure 14 and Figure 15. Additionally, can be observed a more brittle behavior of the $\mathrm{C} 10$ model in $\mathrm{x}$-direction which failed before reaching the collapse prevention limit state (Figure 14). This sudden break of the pushover curve occurs due to the non- 
convergence of the analysis from ZeusNL software which leads to structure collapse.

In the y direction, the building exhibits more ductility compared with other direction. In all cases it is observed that region between LS and $\mathrm{CP}$ performance level is associated with negative slope of the pushover curve.

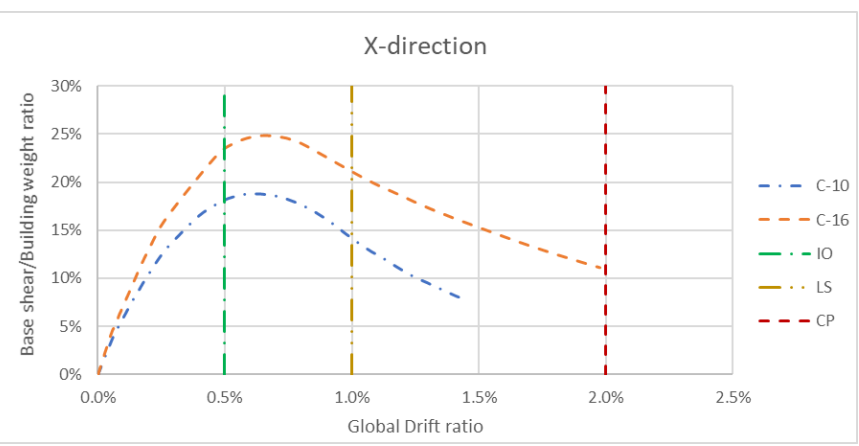

Figure 14: Pushover results for $\mathrm{C} 10$ and $\mathrm{C} 16$ together with limit states in $\mathbf{X}$-direction



Figure 15: Pushover results for $\mathrm{C} 10$ and $\mathrm{C} 16$ together with limit states in $\mathrm{Y}$-direction

\subsection{Incremental Dynamic Analysis results}

More than one thousand dynamic analyses are performed for the case study building in both directions modeled with concrete C16 and C10. Values from each earthquake records are used to generate 18 IDA curves for each of the four models. Moreover, limit states are defined for each of the IDA curve for the Immediate Occupancy, Collapse Prevention and Global Instability as shown in the figures 16-19.

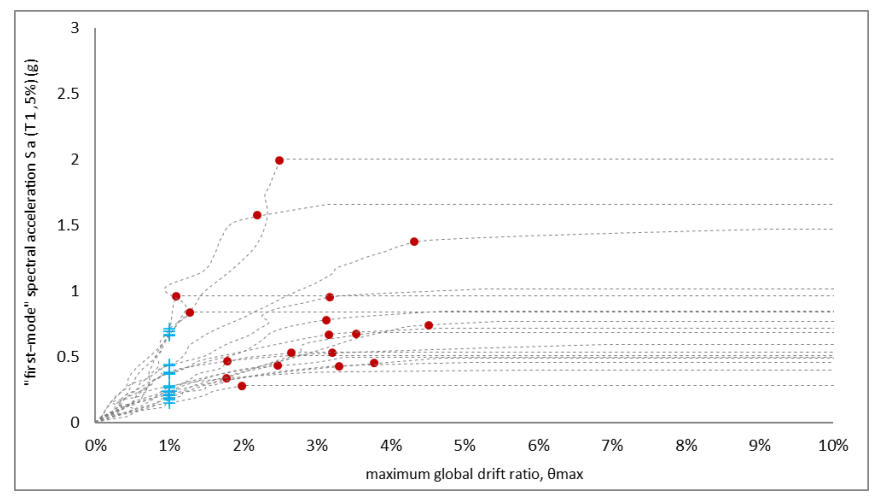

Figure 16: IDA Curves and Limit States for C16 - X direction

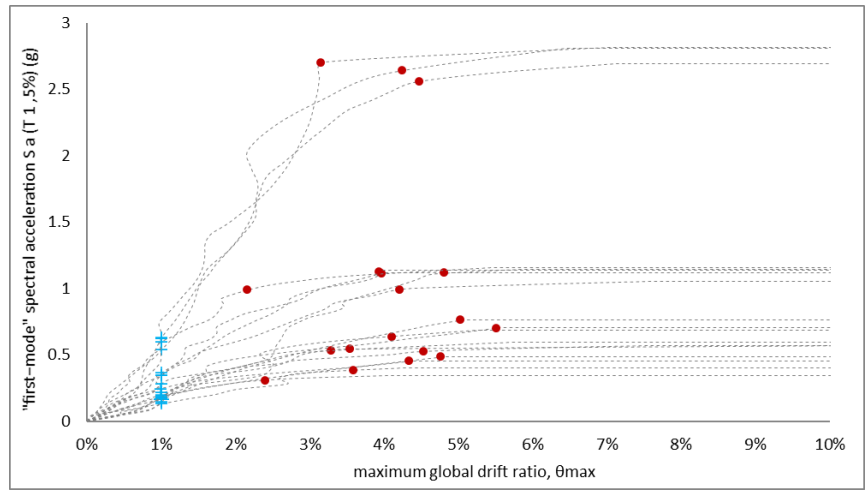

Figure 17: IDA Curves and Limit States for C16 - Y direction

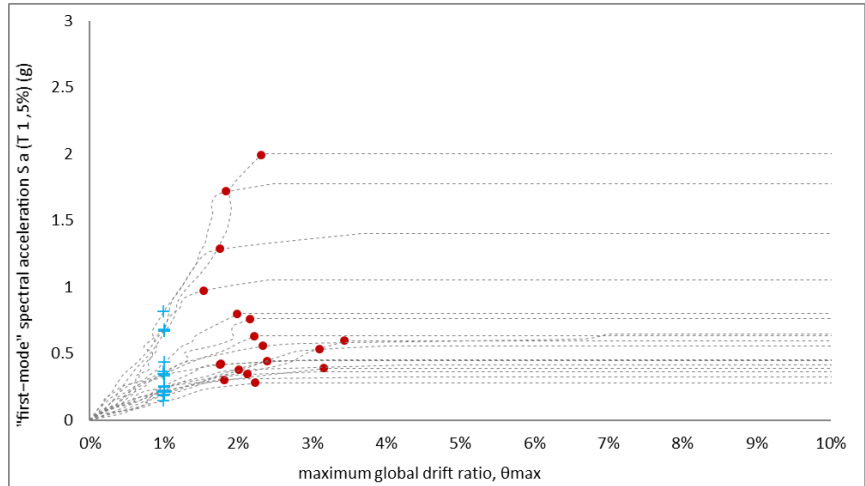

Figure 18: IDA Curves and Limit States for C10 - X direction

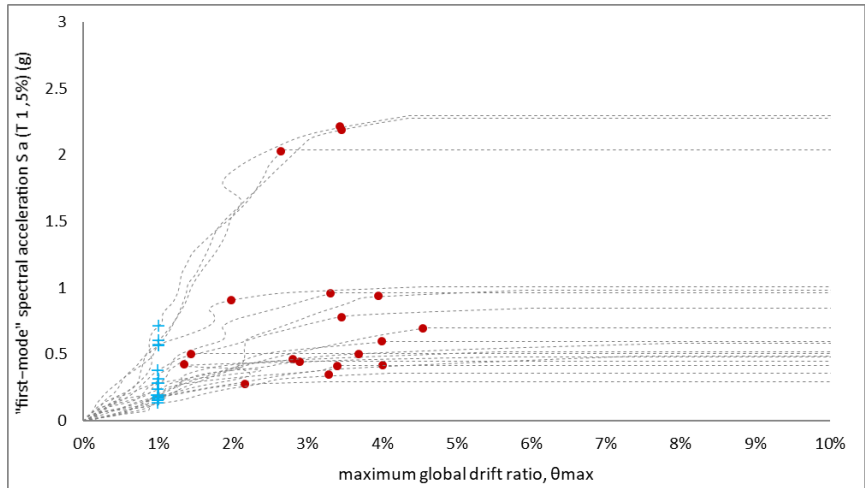

Figure 19: IDA Curves and Limit States for C10 - Y direction

From the graphs, it is clearly observed the softening and hardening of the IDA curves until the global instability (GI) is reached. GI is represented with flatlines on each of the curves indicating the total collapse of the building. Together with IDA curves, the limit states are plotted. With "+" sign is shown the immediate occupancy which corresponds to $1 \%$ of the damage measure. Furthermore, values from the collapse prevention limit states are calculated considering $20 \%$ of the elastic slope or $10 \%$ of the damage measure and plotted with dots in the graphs. Once the IDA curves and limit states are ready, it is more practical to observe the effect of each earthquake record on our building. As can be seen from the graphs, it is obvious that all models will fail in a range from about $0.3 \mathrm{~g}$ to $0.9 \mathrm{~g}$ from most of the earthquakes. However, earthquakes such as: Friuli (PGA = 0.345), Loma Prieta WAHO 000 (PGA = 0.370), Loma Prieta WAHO $090(\mathrm{PGA}=0.638)$ will force the structure to fail later, thus at a higher intensity measure. This phenomenon is better observed especially in the y-direction of the models (Figure 17 and Figure 19). 


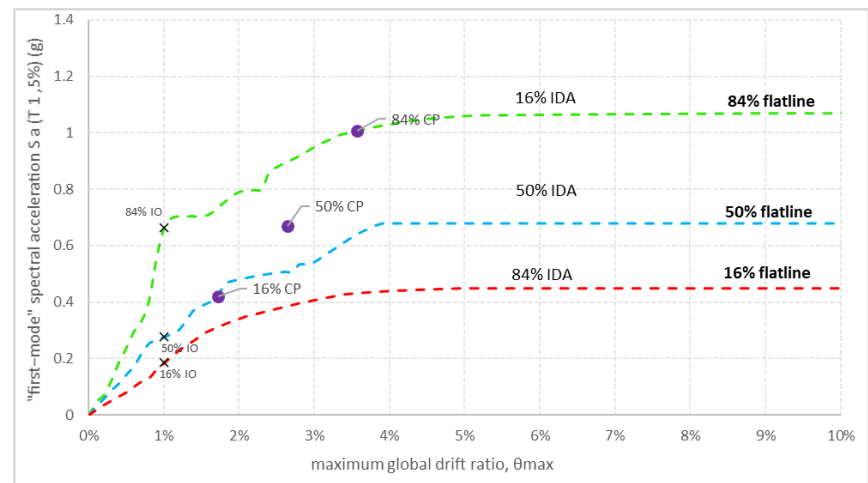

Figure 20: IDA Fractiles and Limit States for C16 - X direction

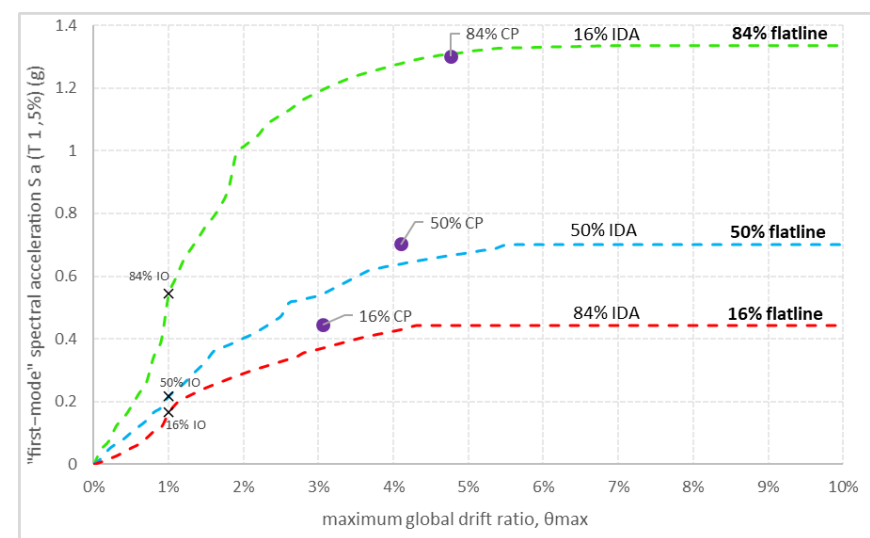

Figure 21: IDA Fractiles and Limit States for C16 - Y direction

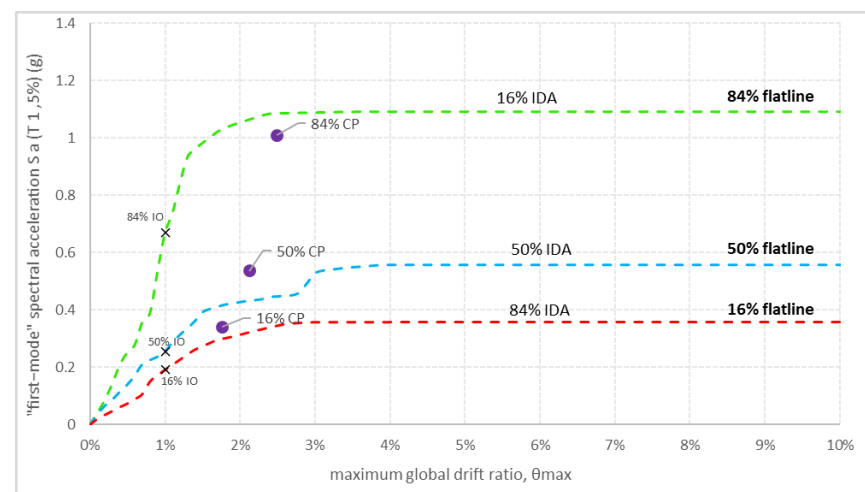

Figure 22: IDA Fractiles and Limit States for C10 - X direction

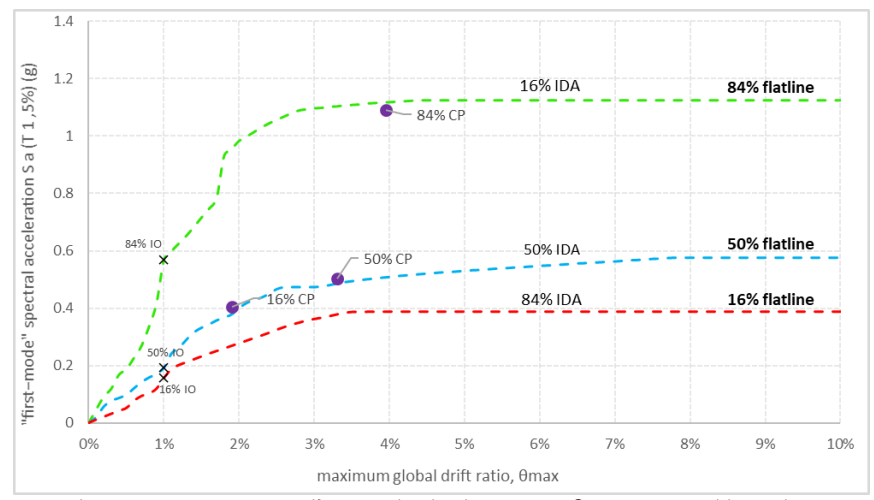

Figure 23: IDA Fractiles and Limit States for C10 - Y direction

On the other hand, the information provided by the summarization of the IDA curves into $16 \%, 50 \%$ and $84 \%$ fractiles is remarkable especially in terms of seismic performance calculation. Consequently, it is possible to observe the response of the structure in any intensity measure increment, from the initial condition until total collapse of the building takes place as shown in the figures 20-23. For instance, when the intensity measure is equal to $0.4 \mathrm{~g}$, it is observed that $16 \%$ of the records produce $\theta_{\max } \leq 0.8 \%, 50 \%$ of the records produce $\theta_{\max } \leq$ $1.6 \%$ and $84 \%$ of the records produce $\theta_{\max } \leq 2.9 \%$ for the C-16 x direction model (Figure 20 ). Similarly, fractiles can be used to gather more information on the intensity measure for a target displacement. Thus, C16 y-direction model will reach $\theta_{\max }=2.0 \%$, when $16 \%$ of the records are scaled to $0.98 \mathrm{~g}, 50 \%$ of the records when $\mathrm{Sa}(\mathrm{T} 1,5 \%)=0.38 \mathrm{~g}$ and $84 \%$ of the records when $\mathrm{Sa}(\mathrm{T} 1,5 \%)=0.28 \mathrm{~g}$ (Figure 21 ). Moreover, the limit states are very helpful for performance levels of the structure. As shown graphically, a rapid comparison can be done based on different concrete classes. Hence, in x-direction of the C16 model, $16 \%$ of the IDA records reached IO at $\mathrm{Sa}(\mathrm{T} 1,5 \%)=0.19,50 \%$ at $\mathrm{Sa}(\mathrm{T} 1,5 \%)=0.28$ and $84 \%$ at $\mathrm{Sa}(\mathrm{T} 1,5 \%)=0.66$ (Figure 20 ). While in the same direction of $\mathrm{C} 10$ model, IO limit state is reached at $\mathrm{Sa}(\mathrm{T} 1,5 \%)=$ $0.19 \mathrm{~g}$ by $16 \%$ of the records, $50 \%$ of the records at $\mathrm{Sa}(\mathrm{T} 1,5 \%)=0.25 \mathrm{~g}$ and $84 \%$ of the records at $\mathrm{Sa}(\mathrm{T} 1,5 \%)=0.67 \mathrm{~g}$ (Figure 22). From the collapse prevention limit state can be easily demonstrated the ductility difference between two concrete classes. For example, C16 y-direction will reach CP limit state at $\theta_{\max } \leq 4.1 \%$ by $50 \%$ of the records (Figure 21). On the other hand, we can observe an early $\mathrm{CP}$ point for the same direction of $\mathrm{C} 10$ model at $\theta_{\max } \leq 3.3 \%$ (Figure 23). In the same trend it could be interpreted the response of the building for the total collapse. For instance, $50 \%$ of the records force the C16-Xdirection model to fail at $\mathrm{Sa}(\mathrm{T} 1,5 \%)=0.68 \mathrm{~g}$ (Figure 20) and $\mathrm{C} 10-\mathrm{X}-$ direction model at $\mathrm{Sa}(\mathrm{T} 1,5 \%)=0.56 \mathrm{~g}$ (Figure 22).

\subsection{SPO versus IDA}

Another comparison method between the Incremental Dynamic Analysis and Nonlinear Static Pushover is to express the SPO curves in the intensity measure and damage measure parameters while plotting the dynamic pushover curve. This can be done by properly scaling the damage measure axis of the pushover curve to match the elastic region of the IDA curve. This is shown in the graphs by the equal displacement slope. Plotting both curves in the same graph can be very helpful to find the correlation among different stages of the structural damage. Usually, the SPO curves are plotted as maximum base shear versus the maximum global drift. Thus, it needs to be transformed as IM and DM values. Since the damage measure coincides same for both structures as global drift ratio, the intensity measure can be calculated by dividing the base shear force by the building's weight and adjust the elastic region of the static pushover curve to match the IDA's one.

The Incremental Dynamic Analysis curves are plotted as $50 \%$ fractile on the same graph with SPO curves. An elastic line called "elastic displacement" is plotted together with pushover curves to show the range of the elastic slope. Figures 24-27 demonstrate the example of IDA versus SPO curves for both structures, in $\mathrm{x}$ - and $\mathrm{y}$-directions.

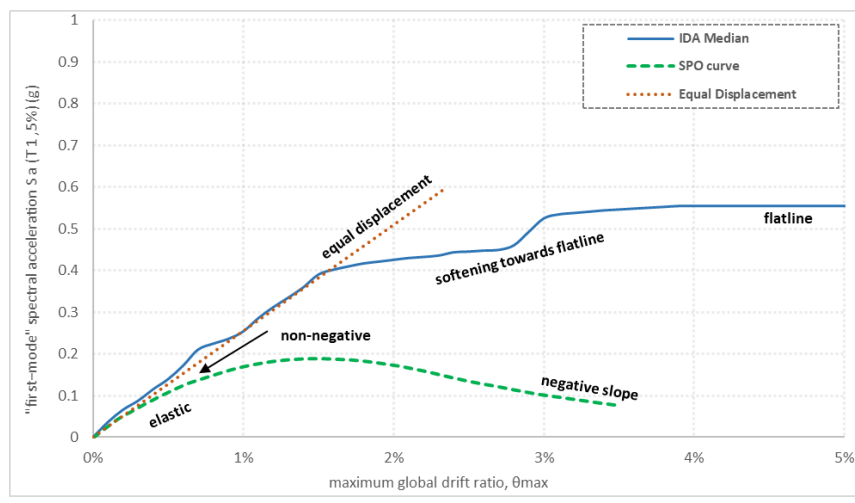

Figure 24: The SPO versus the IDA median for C10, $\mathrm{X}$-direction. 


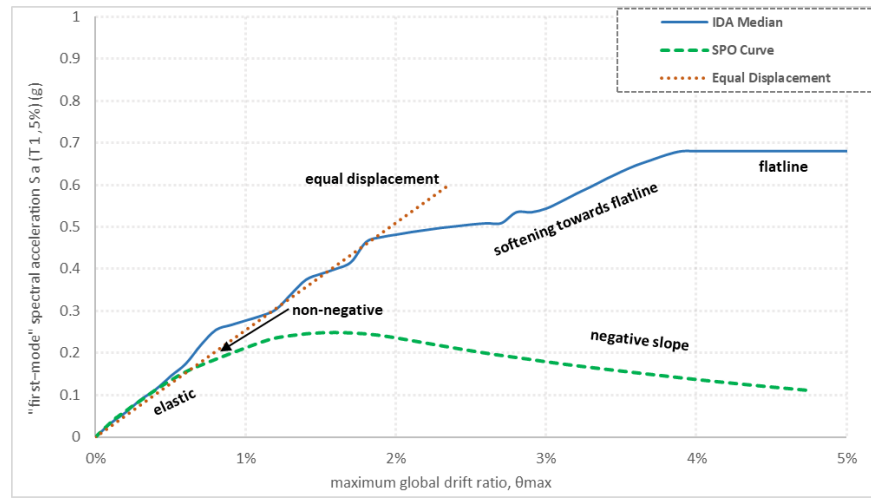

Figure 25: The SPO versus the IDA median for C16, $\mathbf{x}$-direction.

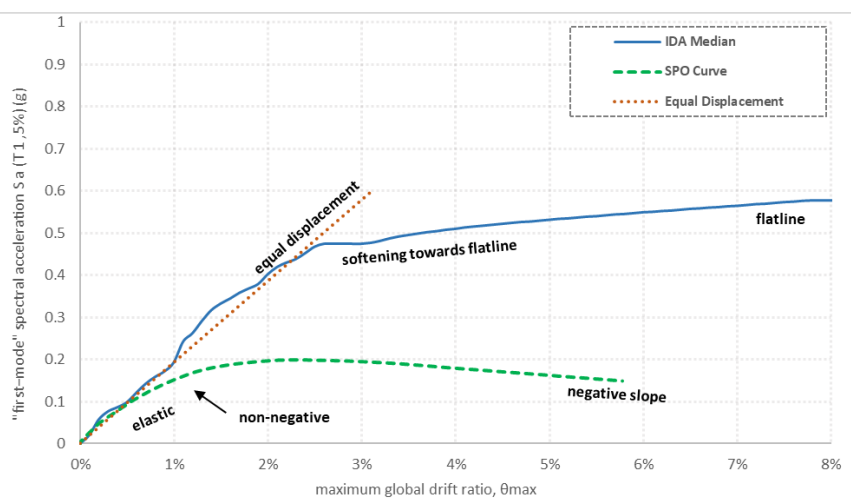

Figure 26: The SPO versus the IDA median for C10, Y-direction.

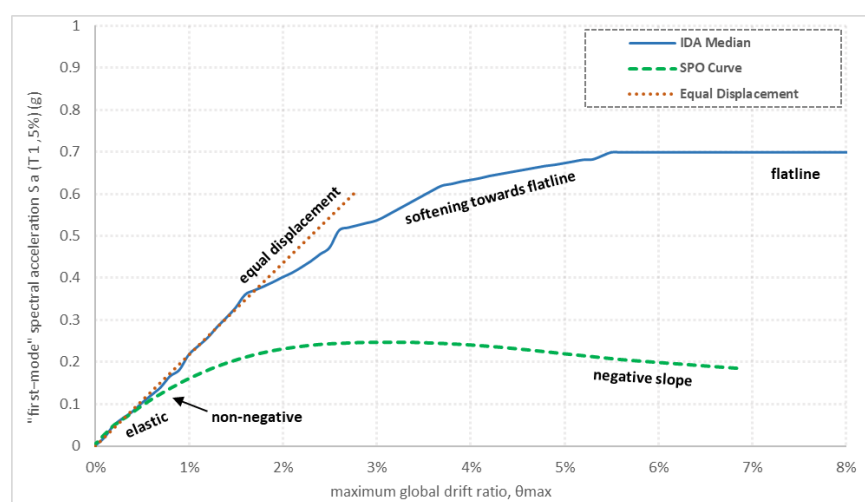

Figure 27: The SPO versus the IDA median for C16, Y-direction.

The comparison of the SPO and IDA curves is done for the C10 and C16 buildings in both directions using a set of eighteen earthquake ground motion records while pushover analyses are performed using triangular load pattern. A strong relationship is observed between IDA median and the SPO curve while evaluating the structural performance as presented below: While comparing static pushover curve and IDA curve, it is observed that elastic region of SPO curves match well with elastic region of the IDA median. This is illustrated in all plots by the help of equal displacement rule.

The negative slope of the static pushover curve is translated by the softening region of the IDA curve. Hence, softening of the IDA or negative slope of the SPO curves can lead to the collapse of the building represented by flatlines in the dynamic pushover median. Essentially, the last SPO values which approach to zero IM values, indicates the end of the Incremental Dynamic Analysis which is demonstrated by the end of the horizontal lines (also called as IDA flatlines) [11, 35].

\section{Conclusions}

In this study the seismic performance estimation is presented for an old reinforced concrete building in Albania. This case study was designed in 1982 according to old Albanian building code. The case study is a moment resisting frame template residential building constructed without shear walls. Zeus-NL software is used for the mathematical model considering both of its transverse frames. From the investigations conducted during the November 26 earthquake, it has been observed that concrete aging is one of the main factors for the weak performance of especially old buildings. Hence, in this study the building is modeled using $\mathrm{C} 16$, as given in the blueprint, and with C10 to represent better the actual condition of the concrete class of the case study building. Demand calculations are performed using one of the recent methods used in the Performance-Based Earthquake Engineering (PBEE) known as Incremental Dynamic Analysis (IDA). To perform IDA curves, a set of 18 ground motion records is selected, bearing no marks of directivity. In addition, a methodology is presented for the development of the IDA curves by properly selecting a suitable intensity measure. For this study it is selected (IM-5\% damped first mode spectral acceleration) and damage measure (DMmaximum global drift ratio). Moreover, the limit states are defined as Immediate Occupancy (IO), Collapse Prevention (CP) both outlined in FEMA guidelines and Global Instability (GI). Furthermore, IDA curves are summarized in $16 \%, 50 \%$ and $84 \%$ fractiles. Finally, is introduced a detailed interpretation of the structural response in terms of IM as well as DM for the seismic evaluation. On the other hand, the conventional method, such as static nonlinear analysis (Pushover) are performed as well. Pushover analysis is applied using an inverse triangular load pattern defined in Zeus-NL software. The limit states are defined based on FEMA 356 guidelines and modified for intermediate moment frames. Compared with Incremental Dynamic Analysis, pushover requires less time to perform the structural assessment. Therefore, a comparison between conventional and modern methods is much useful for the performance evaluation of the buildings. From the results obtained, a strong relationship is investigated between IDA median and static pushover curves. It is observed that elastic region for all curves matches with each other. At the same time the negative slope of the static pushover curve corresponds to the softening region of the IDA curve. This is a good indicator for the structural collapse illustrated by flatlines in the dynamic pushover curves. Simultaneously, it can be concluded that as SPO curve diminishes, the IDA median ends with a horizontal, constant fractiles, both indicating the total collapse of the building. According to the outcomes of this study, it can be concluded that the main reason for the damage in this building type is the reduction of the amount of reinforcement from the ground floor to the first floor by about $1 / 3$. Moreover, the low strength of the concrete used in the construction of some of these buildings (compressive strength results in approximately $50 \%$ less than required) and the use of flat rebar contribute to these failures.

\section{Declaration of Conflict of Interests}

The authors declare that there is no conflict of interest. They have no known competing financial interests or personal relationships that could have appeared to influence the work reported in this paper.

\section{References}

[1] Elnashai A.S., Sarno L.D., «Fundamentals of Earthquake Engineering,》 John Wiley \& Sons, Ltd., London, 2008.

[2] K. 2-78, «Technical design regulations for construction works in seismic regions,» Technical Design Regulations, pp. 12-48, 1978.

[3] Crowley, H., Despotaki, V., Silva, V, «Model of seismic design lateral force levels for the existing reinforced concrete European building stock.,» Bull Earthquake Eng 19, cilt 3, no. https://doi.org/10.1007/s10518-021-01083-, p. 2839-2865, 2021. 
[4] Aliaj, Shyqyri \& Kociu, Siasi \& Muco, Betim \& Sulstarova, Eduard, "Seismicity, seismotectonics and seismic hazard assessment in Albania.,» 2010.

[5] Shkodrani N, Bilgin H, Hysenlliu M., «Influence of interventions on the seismic performance of URM buildings designed according to pre-modern codes.,» Journal of Research on Engineering Structures and Materials, cilt 7, no. 2, pp. 315330, 2021.

[6] Bilgin, H.; Hysenlliu, M., "Comparison of near and far-fault ground motion effects on low and mid-rise masonry buildings.,» Journal of Building Engineering, cilt 30, no. https://doi.org/10.1016/j.jobe.2020.101248., 2020.

[7] Marjo Hysenlliu,Huseyin Bilgin,Altin Bidaj,Marsed Leti, «Structural performance of URM school buildings during the 2019 Albania earthquakes.,» Challenge Journal of Structural Mechanics, cilt 6, pp. 215-231, 2020.

[8] Ercan Işık,Ehsan Harirchian,Huseyin Bilgin,Kirti Jadhav, «The effect of material strength and discontinuity in RC structures according to different site-specific design spectra.,» Research on Engineering Structures and Materials, 2021.

[9] Shkodrani N. and Bilgin H. , "Seismic performance of existing low-rise URM buildings considering the addition of new stories.," Structural Engineering and Mechanics, An International Journal, cilt 6, no. 79, pp. 767-777, 2021.

[10] Işık, E., Harirchian, E., Bilgin, H., and Jadhav, K., «The effect of material strength and discontinuity in RC structures according to different site-specific design spectra.,» Journal of Research on Engineering Structures and Materials, , no. http://dx.doi.org/10.17515/resm2021.273st0303, 2021.

[11] Dimitros Vamvatiskos, Cornell C.A, «Incremental dynamic analysis. Earthquake Engineering,》 doi:10.1002/eqe.141, pp. 491-514, 2002.

[12] A. Elnashai, "Zeus NL - A system for Inelastic Analysis of Structures,》 Urbana-Champaign: Creating a Multi-hazard Approach to Engineering, 2002.

[13] A.S Elnashai, V. Papanikolaou, D.H Lee, «ZEUS-NL User Manual,» Mid-Amerika Earthquake Center, University of Illinois at Urbana-Champaign, 2002.

[14] D. Vamvatsikos, «Seismic Performance Capacity and Reliability of Structures as seen,» Stanford: Stanford University, 2002.

[15] Erberic M.A., Elneshai AS., «Fragility analysis of flat-slab structures,» Engineering Structures, cilt 7, no. 26, pp. 937-948, 2004.

[16] Jeong S.H., Elnashai A.S, "Analytical assessment of an irregular RC frame,» ASCE Jounal Structure Engineering, cilt 1, no. 9, pp. 95-128, 2005.

[17] Hueste M.D., Bai J.W, «Seismic retrofit of reinforced concrete flat-slab structures,» Engineering Structures, cilt 6, no. 29, pp. 65-77, 2007.

[18] Hüseyin Bilgin, Marsed Leti, «Structural damages of Durrës (Albania) Earthquake,» \%1 içinde PACE-2021 International Congress on the Phenomenological Aspects of Civil Engineering, Erzurum, Turkey, 2021.

[19] N. Shome, C.A.Cornell, «Probabilistic seismic demand analysis of nonlinear structures,» Stanford: Stanford University, 2002.

[20] PEER, «Pacific Earthquake Engineering Research Center, University of California,» 12 December 2020. [Çevrimiçi]. Available: http://peer.berkeley.edu/.

[21] U. USGS, "Geological Survey, U.S. Department of the Interior,» 12 December 2020. [Çevrimiçi]. Available: https://www.usgs.gov.

[22] FEMA365, "Prestandard and Commentary for the Seismic Rehabilitation of Buildings,» Washington, DC.: Federal Emergency Management Agency, 2000.

[23] ATC-40, «Seismic Evaluation and Retrofit,» SEISMIC SAFETY COMMISSION , California, 1996.

[24] FEMA-440, «Improvement of Nonlinear Static Seismic Analysis Procedures,》 Federal Emergency Management Agency, Washington, D.C., 2005.

[25] Eurocode_8, «Design provisions for earthquake resistance of structures., British Standards Institution., London, 1996.
[26] Ramamoorthy S., Gardoni P., Bravcci J, «Probabilistic demand models and fragility," Journal of Structural Engineering, pp. 1563-1572, 2006.

[27] A.M Mwafy, A.S Elnashai, «Static pushover versus dynamic collapse analysis of RC buildings,» Eng. Struct., vol. 23, pp. 407424, 2001.

[28] P. Spears, «Parameters Influencing Seismic Structural Collapse with Emphasis on Vertical Accelerations and the Possible Related Risks for New and Existing Structures in the Central and Eastern United States,» Blacksburg, VA: Virginia Polytechnic Institude and State University, 2004.

[29] D. Vamvatsikos, C.A Cornell, «Applied Incremental Dynamic Analysis,» EarthquakeSpectra, pp. 523-553, 2003.

[30] Dimitros Vamvatiskos, Fatemeh Jalayer, Alin Cornell, "Application of Incremental Dynamic Analysis to an RCStructure,》 January 2003. [Çevrimiçi]. Available: https://www.researchgate.net. [Erişildi: May 2021].

[31] Nicolas Luco, Allin Cornell, «Structure-specific scalar intensity measures for near-source and ordinary earthquake ground motions,》 USGS, cilt 23, no. 2, pp. 357-392, 2007.

[32] Huseyin Bilgin, Idlir Frangu, «Predicting the seismic performance of typical R/C healthcare facilities: emphasis on hospitals," International Journal of Advanced Structural Engineering, cilt 9, no. 3, pp. 277-292, 2017.

[33] Van Rossum, G., \& Drake Jr, F. L., «Python tutorial. Centrum voor Wiskunde en Informatica Amsterdam,» The Netherlands, 1995.

[34] K. Cherif, "github,» 4 January 2021. [Çevrimiçi]. Available: https://github.com/kawache/Python-B-splineexamples/blob/master/README.md. [Erişildi: 23 June 2021].

[35] Kazantzia A.K., Vamvatsikosb D., Lignosc D.G., «Seismic performance of a steel,» \%1 içinde 11th International Conference on Structural Safety and Reliability (ICOSSAR), 2014.

\section{How to Cite This Article}

Leti, M., Bilgin, H., Seismic performance assessment of a MomentFrame Reinforced Concrete building typology., Civil Engineering Beyond Limits, 1(2022), 1544. https://doi.org/10.36937/cebel.2022.1544 